6 Lubin JH, Burns PE, Blot WJ, et al. Risk factors for breast cancer in women in northern Alberta, Canada, as related to age at diagnosis. $7 N C I$ 1982;68: 211-7.

7 Janerich DT, Hoff MB. Evidence for a cross-over in breast cancer risk factors. Am 7 Epidemiol 1982;116:737-42.

8 Ron E, Lubin F, Wax Y Re: "Evidence for a cross-over in breast cancer risk factors." Am f Epidemiol 1984;119:139-40.

9athak DR, Speizer FE, Willet WC, al Parity and breast cancer risk: possible effect on age at diagnosis. Int $\mathcal{F}$ Cancer 1986;37:21-5.

10 Woods KL, Smith SR, Morrison JM. Parity and breast cancer: evidence of dual effect. BrMed f 1980;281:419-21.

11 Miller $\mathrm{AB}$, Bulbrook RD. UICC multidisciplinary project on breast cancer: the epidemiology, aetiology and prevention of breast cancer. Int $\mathcal{F}$ Cancer 986;37:173-7.

2 Toti A, Agugiaro S, Amadori D, et al. Breast cancer risk factors in Italian women: a multicentric case-control study. Tumori 1986;72:241-9.

13 La Vecchia C, Decarli A, Parazzini F, et al. General epidemiology of breast cancer in northern Italy. Int I E pidemiol 1987; 16:347-55.

14 Breslow NE, Day NE. Statistical methods in cancer research. Lyons:
International Agency for Research on Cancer, 1980. (IARC Scientific Publications No 32 .

15 Baker RJ, Nelder JA. The GLIM system. Oxford: Numerical Algorithms Group, 1978

16 Russo J, Tay LK, Russo IH. Differentiation of the mammary gland and susceptibility to carcinogenesis. Breast Cancer Res Treat 1982;2:5-73.

17 Peto R. Epidemiology, multistage models, and short term mutagenicity tests. In: Hiatt $\mathrm{HH}$, Watson JD, Winsten JA eds. Oring of human In: Hiatt HH, Watson JD, Winsten JA, eds. Origins of human cancer. Cold 18 Day NE, Brown CC. Multistage models and primary prevention of cancer. fNCI 1980;64:977-89.

19 Moolgavkar SH, Day NE, Stevens RG. Two-stage model for carcinogenesis epidemiology of breast cancer in females. 7 NCI 1980;65:559-69.

20 Russo IH, Russo J. From pathogenesis to hormone prevention of mammary carcinogenesis. Cancer Surv 1986;5:649-70.

21 Pike MC, Krailo MD, Henderson BE, et al. "Hormonal" risk factors, "breas tissue age" and the age-incidence of breast cancer. Nature 1983;303:767-70

(Accepted 28 fune 1988)

\title{
Increased mortality of preterm infants transferred between tertiary perinatal centres
}

\author{
Ellen Bowman, Lex W Doyle, Laurence J Murton, R Neil D Roy, William H Kitchen
}

\begin{abstract}
Over 18 months almost one quarter of infants born before 30 weeks' gestation in a tertiary perinatal centre who required intensive care had to be transferred to other tertiary centres because intensive care facilities were fully occupied. When infants with lethal congenital malformations were excluded half of the 34 infants who were transferred died; this was twice the mortality (24\%) in the 111 infants remaining. The difference between the groups was significant (relative odds $=3 \cdot 1$ ) and remained so after adjustment for any discrepancies in gestational age (relative odds $=4 \cdot 0$ ). After adjustment for potential confounding variables by logistic function regression the risk of dying for those transferred remained significantly higher than that for infants who remained (relative odds $=4.6,95 \%$ confidence interval $1 \cdot 8$ to $12 \cdot 1$ ).
\end{abstract}

As the requirement for neonatal intensive care is episodic and unpredictable more flexibility has to be built into the perinatal health care system to enable preterm infants delivered in tertiary perinatal centres to be cared for where they are born.

\section{Introduction}

Mortality in preterm infants increases with decreasTransport Service (NETS) Victoria, Australia Ellen Bowman, FRACP, deputy director

R Neil D Roy, FRACP, director

Division of Paediatrics, Royal Women's Hospital, Melbourne

Laurence J Murton, FRACP, director of neonatal intensive care unit

\section{Departments of Obstetrics} and Gynaecology, University of Melbourne, Parkville, 3052 Melbourne Lex W Doyle, FRACP, senior lecturer

William H Kitchen, FRACP, first assistant

Correspondence to: $\mathrm{Dr}$ Doyle. influences survival is being born outside a tertiary perinatal centre; transferring such infants to tertiary centres improves their survival. ${ }^{1}$ We studied the fate of preterm infants born in one tertiary centre who required intensive care but had to be transferred to other centres because of lack of facilities in the hospital of birth.

\section{Patients and methods}

During 18 months from 1 January 1986 there were Melbourne, the largest of the three tertiary perinatal centres in the state of Victoria. After birth 396 (4\%) infants required intensive care. Criteria for admission to the intensive care unit included the need for assisted ventilation or an indwelling arterial line. Over the 18 months $63(16 \%)$ of these infants born in other centres (two perinatal, one neonatal only) in Melbourne because the intensive care facilities were full.
Data on perinatal variables likely to influence survival were recorded (table I). The obstetrician's estimate of gestation, based on menstrual history or early ultrasound examination, or both, was accepted as accurate. Babies with lethal congenital abnormalities and those transferred immediately after birth because they needed a major operation (unavailable in our hospital) were excluded from the final analysis. As infants born at $\geqslant 30$ weeks' gestation are likely to survive whether they are transferred or not we were particularly interested in the outcome of those born at $<30$ weeks' gestation.

In infants born before 30 weeks' gestation mortality was compared between the group who stayed in the hospital of birth and the group transferred, firstly, by $\chi^{2}$ analysis with no adjustment for confounding factors; secondly, by the Mantel-Haenszel $\chi^{2}$ test with adjustment for gestational $\mathrm{age}^{2}$; and, finally, by logistic function regression with adjustment for other variables, listed in table I. Table $I$ also shows the proportion of babies intubated by the time of the first analysis of blood gas tensions and the ventilator settings for those infants; these variables give an assessment of the severity of respiratory disease in the first hours after birth. To see whether mortality might

TABLE I-Perinatal variables in preterm infants (24-29 weeks' gestation) remaining in hospital of birth or transferrd to another tertiary perinatal centre (infants with lethal congenital abnormalities were excluded) 10455 live births at the Royal Women's Hospital, the hospital had to be transferred to one of three

\begin{tabular}{|c|c|c|}
\hline Perinatal variable & $\begin{array}{l}\text { Infants } \\
\text { remaining } \\
(\mathrm{n}=111)\end{array}$ & $\begin{array}{c}\text { Infants } \\
\text { transferred } \\
(\mathbf{n}=34)\end{array}$ \\
\hline $\begin{array}{l}\text { Mean (SD) gestational age (completed } \\
\text { weeks) } \\
\text { Mean (SD) birth weight (g) } \\
\text { Mean (SD) inspired oxygen (\%) } \\
\text { Median (interquartile range) Apgar score: } \\
\text { At } 1 \text { minute } \\
\text { At } 5 \text { minutes } \\
\text { Median (interquartile range) time to first } \\
\text { arterial blood gas analysis (minutes) } \\
\text { No (\%) male } \\
\text { No }(\%) \text { transferred in utero } \\
\text { No }(\%) \text { resulting from multiple pregnancies } \\
\text { No }(\%) \text { intubated }{ }^{\star}\end{array}$ & $\begin{array}{c}27 \cdot 3(1 \cdot 4) \\
1023(256) \\
66 \cdot 4(22 \cdot 8) \\
5(3 \text { to } 6) \\
8(7 \text { to } 9)\end{array}$ & $\begin{array}{c}27 \cdot 0 \quad(1 \cdot 5 \\
1002(265) \\
62 \cdot 1 \quad(20 \cdot 0 \\
\\
5 \quad(4 \text { to } 7) \\
8(7 \text { to } 9)\end{array}$ \\
\hline \multicolumn{3}{|c|}{ Intubated infants ${ }^{\star}$} \\
\hline $\begin{array}{l}\text { Mean }(\mathrm{SD}) \text { inspired oxygen }(\%) \\
\text { Mean }(\mathrm{SD}) \text { peak pressure }\left(\mathrm{cm} \mathrm{H}_{2} \mathrm{O}\right) \\
\text { Mean }(\mathrm{SD}) \text { end expiratory pressure } \\
\quad\left(\mathrm{cm} \mathrm{H}_{2} \mathrm{O}\right) \\
\text { Mean }(\mathrm{SD}) \text { ventilator rate (breaths/minute) }\end{array}$ & $\begin{array}{r}69 \cdot 7(22 \cdot 2) \\
20 \cdot 7(5 \cdot 1) \\
4 \cdot 6(0 \cdot 5) \\
41 \cdot 5(10 \cdot 0)\end{array}$ & $\begin{array}{l}63 \cdot 3(19 \cdot 7) \\
20 \cdot 3(4 \cdot 0)\end{array}$ \\
\hline
\end{tabular}

$\star$ At time of first blood gas analysis. $\dagger p<0.001, \neq p=0.04$. 
be higher when the unit was busy and full the difference in time between the birth of each infant remaining in our unit and the birth of the baby closest in age who had to be transferred was calculated and included in the logistic regression analysis.

As babies from multiple pregnancies are more likely to be transferred and mortality may be higher in multiple births $s^{3}$ all of the preceding analyses were repeated for singleton babies born before 30 weeks' gestation.

Univariate differences between the two groups in discrete perinatal variables were contrasted by $\chi^{2}$ analysis and in continuous variables by the $t$ test or Mann-Whitney $U$ test when the data were skewed. In all statistical tests $\mathrm{p}<0.05$ was considered to be significant.

\section{Results}

Of the infants born at 24-29 completed weeks' gestation who required intensive care, 36 out of 150 (24\%) were transferred; their median age at the time of transfer was 148 minutes (interquartile range 100-213 minutes). One infant was transferred after 5 hours of age because of delay in finding an intensive care cot and organising the transport team. Of the infants of $\geqslant 29$ weeks' gestation, 27 out of 246 (11\%) were transferred; their median age at the time of transfer was 233 minutes (interquartile range 145-290 minutes). Of those who were transferred, two (one born at 24 weeks and the other at 28 weeks) subsequently died from lethal congenital abnormalities. Of those who remained at the hospital, three born at 24-29 weeks and 11 born beyond 29 weeks died from lethal congenital abnormalities. When infants with lethal congenital abnormalities were excluded mortality rose with decreasing gestational age $(\mathrm{p}<0.0001$, table II).

TABLE II-Mortality by gestational age of infants remaining in hospital of birth or transferred to another tertiary perinatal centre (infants with lethal congenital abnormalities were excluded). Values are proportions (percentages) of infants who died

\begin{tabular}{lcccc}
\hline $\begin{array}{l}\text { Gestational age } \\
\text { (completed weeks) }\end{array}$ & \multicolumn{2}{c}{ Infants remaining } & \multicolumn{2}{c}{ Infants transferred } \\
\hline 24 & $5 / 5$ & $(100)$ & $3 / 3(100)$ \\
25 & $1 / 6$ & $(17)$ & $2 / 3$ & $(67)$ \\
26 & $8 / 20$ & $(40)$ & $4 / 4$ & $(100)$ \\
27 & $5 / 25$ & $(20)$ & $3 / 12$ & $(25)$ \\
28 & $5 / 31$ & $(16)$ & $3 / 5$ & $(60)$ \\
29 & $3 / 24$ & $(13)$ & $2 / 7$ & $(29)$ \\
30 & $0 / 33$ & & $0 / 9$ & \\
31 & $1 / 22$ & $(5)$ & $0 / 4$ & \\
32 & $2 / 41$ & $(5)$ & $1 / 4$ & $(25)$ \\
$>32$ & $8 / 112$ & $(7)$ & $1 / 10$ & $(10)$ \\
\hline
\end{tabular}

Mortality in infants born at $\geqslant 30$ weeks' gestation was $7 \%(2 / 27)$ in those transferred and $5 \%(11 / 208)$ in those who remained in the nursery (not significant).

Among the infants born before 30 weeks' gestation mortality was $50 \%(17 / 34)$ in those who were transferred and $24 \%(27 / 111)$ in those who remained at the hospital; this difference was significant (relative odds= $\left.3 \cdot 1, \chi^{2}=6 \cdot 9, p<0 \cdot 01\right)$ and remained so after adjusting mortality for any discrepancies in gestational age (relative odds $=4 \cdot 0, \quad$ Mantel-Haenszel $\chi^{2}=7 \cdot 4$, $\mathrm{p}<0.01)$. In the 17 babies transferred who died causes of death were hyaline membrane disease (12 babies), bronchopulmonary dysplasia (two), cerebroventricular haemorrhage (one), sepsis (one), and unknown (one) In the 27 infants who remained in the hospital who died the causes of death were hyaline membrane disease (20), bronchopulmonary dysplasia (three), sepsis (three), and fetal hydrops (one). The median age at death was 2.5 days (interquartile range 2-10 days) in the transferred group and 3 days (1-13 days) in the infants who remained.
In infants born before 30 weeks' gestation the age at which the arterial blood gases were first sampled was lower in the group who were transferred $(\mathrm{p}<0.001$, table I). This group also contained proportionately more infants from multiple pregnancies $(p=0.04$, table I). Ten infants who were transferred resulted from multiple (twin) pregnancies - three set of twins and four second twins. Two of the second twins ultimately died (one of their twins had died before birth and the other minutes after birth due to severe asphyxia), and the other two survived and were ultimately bigger and healthier than their twins.

The time to the first analysis of arterial blood gas tensions and multiple pregnancies were not significantly associated with mortality before or after adjustment by logistic function regression. Apart from being transferred, the only variables significantly associated with mortality were higher inspired oxygen concentration at the time of the first analysis of arterial blood gas tensions $(p<0.001)$ and decreasing gestational age $(p=0.001)$. After adjustment for these variables by logistic function regression the risk of dying for transferred infants remained significantly higher than that for infants remaining (relative odds $=4 \cdot 6,95 \%$ confidence interval $1 \cdot 8$ to $12 \cdot 1, \mathrm{p}=0 \cdot 002$ ). Other possible counfounders (table I), in particular being born at a time when the unit was busy, were not associated with increased mortality. When all confounders were entered into the logistic regression analysis they had little effect on the association between higher mortality and being transferred (relative odds $=4.4,95 \%$ confidence interval 1.4 to $13 \cdot 8, p=0 \cdot 012$ ). When gestational age was included in the analysis low birth weight was not significantly related to mortality.

When multiple pregnancies were excluded from the analysis mortality was barely affected, being 50\% (12/ 24 ) in singleton infants who were transferred and $26 \%$ $(25 / 97)$ in those who remained (relative odds $=2 \cdot 9, \chi^{2}=$ $4 \cdot 2, \mathrm{p}<0.05)$. As with the whole cohort, in singleton infants the only variables significantly associated with mortality were a higher inspired oxygen concentration at the time of the first analysis of arterial blood gas tensions $(p<0.001)$, decreasing gestational age $(p=$ 0.006 ), and being transferred (relative odds $=6 \cdot 0,95 \%$ confidence interval 2.0 to $18.2, \mathrm{p}<0.002$ ). When all potential confounders were included mortality was still significantly higher in transferred infants (relative odds $=5 \cdot 2,95 \%$ confidence interval $1 \cdot 4$ to $19 \cdot 7, p=$ $0 \cdot 016)$.

\section{Discussion}

Over an 18 month period there was a dramatic increase in the number of preterm infants born in our hospital who required intensive care for conditions not requiring an operation but necessitating transfer to other tertiary centres because our intensive care facilities were full. We were short of facilities because the capacity of the intensive care unit was reduced to $60 \%$ for six months during renovations and because the number of high risk deliveries at the hospital increased.

We are not sure why the mortality of the most immature infants who had to be transferred was so much higher than that of those who remained in the hospital. We reported previously that in infants of 2428 weeks' gestation mortality was higher in those from multiple compared with singleton pregnancies, ${ }^{3}$ but this does not explain the increased mortality in the transferred infants in this study. A disproportionate number of babies resulting from multiple pregnancies were transferred because the policy of the unit was to admit babies in order of arrival and hence facilities were more likely to become fully occupied if two or 
more babies were competing for limited resources. Infants who were transferred did not have substantially more severe respiratory disease than those remaining because the proportions intubated and the ventilator settings were similar in the two groups (table I). Of the measures of respiratory morbidity, only increasing inspired oxygen concentration was independently related to increased mortality; allowance for this variable did not reduce the significance of the increased mortality in the group who were transferred.

The facilities at the time of birth were identical for the babies who were transferred and those who remained; this would not be the case for babies born outside tertiary centres. Though it was often known before birth that the infant would require intensive care and have to be transferred because of lack of facilities, all infants born before 30 weeks were resuscitated by the same paediatric staff, transferred to the intensive care unit, and stabilised as necessary. If anything, the transferred group may have been stabilised sooner, as is suggested by the earlier time of the first analysis of blood gas tensions, though this time was not significantly related to mortality. We speculate, however, that infants in the transferred group were jeopardised by the delay while their transfer was organised and the extra handling that was necessarily associated with transfer, even though all of the three other tertiary centres were within $3 \mathrm{~km}$ of our hospital and the infants were all transferred by a highly skilled team. ${ }^{4}$ Excessive handling has been reported to cause instability and hypoxaemia in critically ill neonates and may have been the crucial factor in the higher mortality found in the transferred group.

An alternative explanation for our results may be that mortality was substantially higher at the three other tertiary perinatal centres. Roughly half of the transferred infants born before 30 weeks went to the tertiary centre that admits only babies born elsewhere. The two other tertiary centres each received roughly a quarter of the infants. Data on mortality relative to gestational age have been published from our hospital ${ }^{3}$ and from one of the tertiary perinatal centres ${ }^{6}$; these data are not substantially different. There are no published data on mortality at any of the centres over the 18 months of this study. Mortality cannot be reliably compared between our unit and that dealing only with neonates because of the selection biases that enable an infant to survive long enough to be admitted elsewhere and because in the neonatal centre infants requiring operations are overrepresented. Data on mortality exist for the state of Victoria but are more reliable, with birth weight as the denominator rather than gestational age. For births from 1982 to 1985, controlling for birthweight distribution, there was no significant difference in mortality between the three tertiary perinatal centres (J Lumley, Victorian perinatal data collection unit, personal communication). We do not have any evidence that the standard of care differs substantially in any of the four centres in Victoria with neonatal intensive care facilities.

In this study we showed that transferring preterm babies soon after birth to another neonatal intensive care unit is not an acceptable solution to the poor distribution of resources within the tertiary centres. Possible strategies available to alleviate the problem include transferring mothers before delivery; increasing the number of nursing staff; and transferring only older, larger, and more stable babies. Each of these strategies has its difficulties.

In our study the mothers of $40 \%$ of the infants born alive at less than 30 weeks' gestation had been transferred before delivery from other hospitals because of complications of pregnancy. This is desirable provided that the infants, when delivered, can be kept in the hospital of birth. If premature delivery is imminent and the infant requires intensive care but no cot is available then every effort should be made to transfer the mother to another tertiary perinatal centre for delivery. This has been, and continues to be, the practice of our hospital. Arranging to transfer the mother is, however, time consuming. Moreover, predicting the time of delivery is not always possible, and it may still be better for tertiary centres to admit the mother before delivery even if the baby has to be transferred again after birth rather than let the baby be born in a centre with inadequate perinatal facilities.

Moving the baby to the facilities after birth seems not to be the best solution. The only other alternative is to move the facilities to the infant. Buying more ventilators, however, will not solve the problem; what is most lacking is skilled nursing staff. To meet our needs funding for additional nursing staff was recently approved; this will enable us to provide assisted ventilation for 10 infants rather then the eight we can currently treat. Once suitably qualified nursing staff are found we will be able to reduce the number of infants transferred. Another solution may be to create a pool of skilled nursing staff who are available at short notice to work when needed.

If a transfer after birth is inevitable it may be better to transfer an older, more stable baby who nevertheless requires intensive care rather than a younger and less stable one. This would be undesirable and unacceptable to most families, who are just starting to cope with their small, sick infant. Moreover, transfer could be detrimental even to older and more stable infants.

Whatever the solution, because the requirement for neonatal intensive care is episodic and unpredictable more flexibility has to be built into the perinatal health care system to enable preterm infants born in tertiary perinatal centres to be cared for where they are born.

1 Kitchen W, Ford G, Orgill A, et al. Outcome in infants with birth weight 500 to $999 \mathrm{gm}$ : a regional study of 1979 and 1980 births. $\mathcal{F}$ Pediatr 1984;104:921-7. 2 Mantel N, Haenszel W. Statistical aspects of the analysis of data from retrospective studies of disease. $\exists N C I$ 1959;22:719-48.

3 Kitchen W, Ford GW, Doyle LW, et al. Cesarean section or vaginal delivery at 24 to 28 weeks' gestation: comparison of survival and neonatal and two-year morbidity. Obstet Gynecol 1985;66:1079-87.

4 Roy RND, Kitchen WH. NETS: a new system for neonatal transport. Med $\mathcal{f}$ Aust 1977;2:855-8.

5 Long JG, Philip AGS, Lucey JF. Excessive handling as a cause of hypoxemia Pediatrics 1980;65:203-7.

6 Yu VYH, Loke HL, Bajuk B, Szymonowicz W, Orgill AA, Astbury J. Prognosis for infants born at 23 to 28 weeks' gestation. Br Med $\mathcal{J}$ 1986;293:1200-3.

(Accepted 19 fuly 1988) 